Review began 11/27/2021 Review ended 12/06/2021 Published 12/09/2021

๑) Copyright 2021

Asai et al. This is an open access article distributed under the terms of the Creative Commons Attribution License CC-BY 4.0. which permits unrestricted use, distribution, and reproduction in any medium, provided the original author and source are credited.

\section{Elite Diving Athlete With Traumatic Growth Plate Injury of the Proximal Humerus: A Case Report}

\author{
Reo Asai ${ }^{1}$, Masaki Tatsumura ${ }^{2}$, Yuta Tsukagoshi ${ }^{3}$, Masashi Yamazaki ${ }^{4}$ \\ 1. Department of Orthopaedics, Tsukuba Medical Center Hospital, Tsukuba, JPN 2. Department of Orthopaedic Surgery \\ and Sports Medicine, Tsukuba University Hospital Mito Clinical Education and Training Center, Mito Kyodo General \\ Hospital, Mito, JPN 3. Department of Paediatric Orthopaedic Surgery, Ibaraki Children's Hospital, Mito, JPN 4. \\ Department of Orthopaedic Surgery, Faculty of Medicine, University of Tsukuba, Tsukuba, JPN
}

Corresponding author: Masaki Tatsumura, tatsumura@md.tsukuba.ac.jp

\section{Abstract}

Growth plate injury of the proximal humerus is rare. We herein report a traumatic growth plate injury of the proximal humerus in an elite diving athlete. A 16-year-old female diving athlete injured her left shoulder during $7.5 \mathrm{~m}$ platform hands-first diving practice. At the first visit, she presented with upper left shoulder tenderness and left shoulder range-of-motion limitation. There was no fracture or dislocation on X-ray and computed tomography (CT), but magnetic resonance imaging (MRI) showed a high-intensity zone in the left lateral epiphysis of the proximal humerus. We treated her conservatively by rest with sling and rehabilitation. She partially restarted diving practice five weeks post-injury and returned to competition eight weeks post-injury. Even if there is no sign of fracture or dislocation, we should consider MRI for patients who are before the age of growth plate closure.

Categories: Pediatrics, Orthopedics, Trauma

Keywords: mri, proximal humerus, growth plate injury, shoulder pain, competitive diving

\section{Introduction}

Growth plate injury of the proximal humerus is a rare injury [1] that can cause early growth plate closure and lead to angular deformity or length discrepancy [2]. Despite the high injury incidence, injury reports in competitive diving are few [3], and we herein report a case of traumatic growth plate injury of the proximal humerus for the first time in an elite diving athlete.

\section{Case Presentation}

A 16-year-old female diving athlete, with no past dislocation or pain history, injured her left shoulder during diving practice (Figure 1). When diving from a $7.5 \mathrm{~m}$ platform (Figure 2), incomplete hands-first entry forced abduction and external rotation of her left shoulder joint. Left shoulder pain occurred soon after and did not improve, so she visited our hospital two days post-injury. 


\section{Cureus}

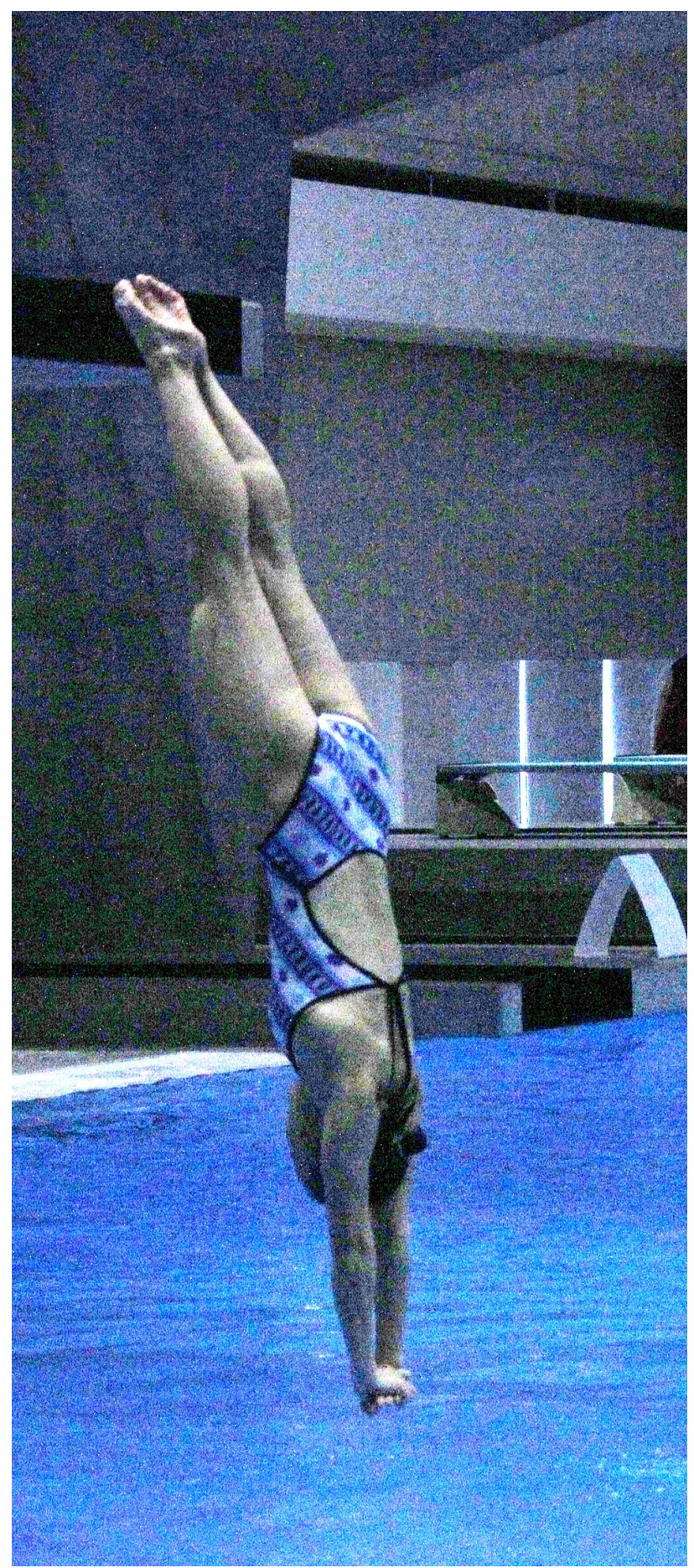

FIGURE 1: Water entry at hands-first diving. 


\section{Cureus}

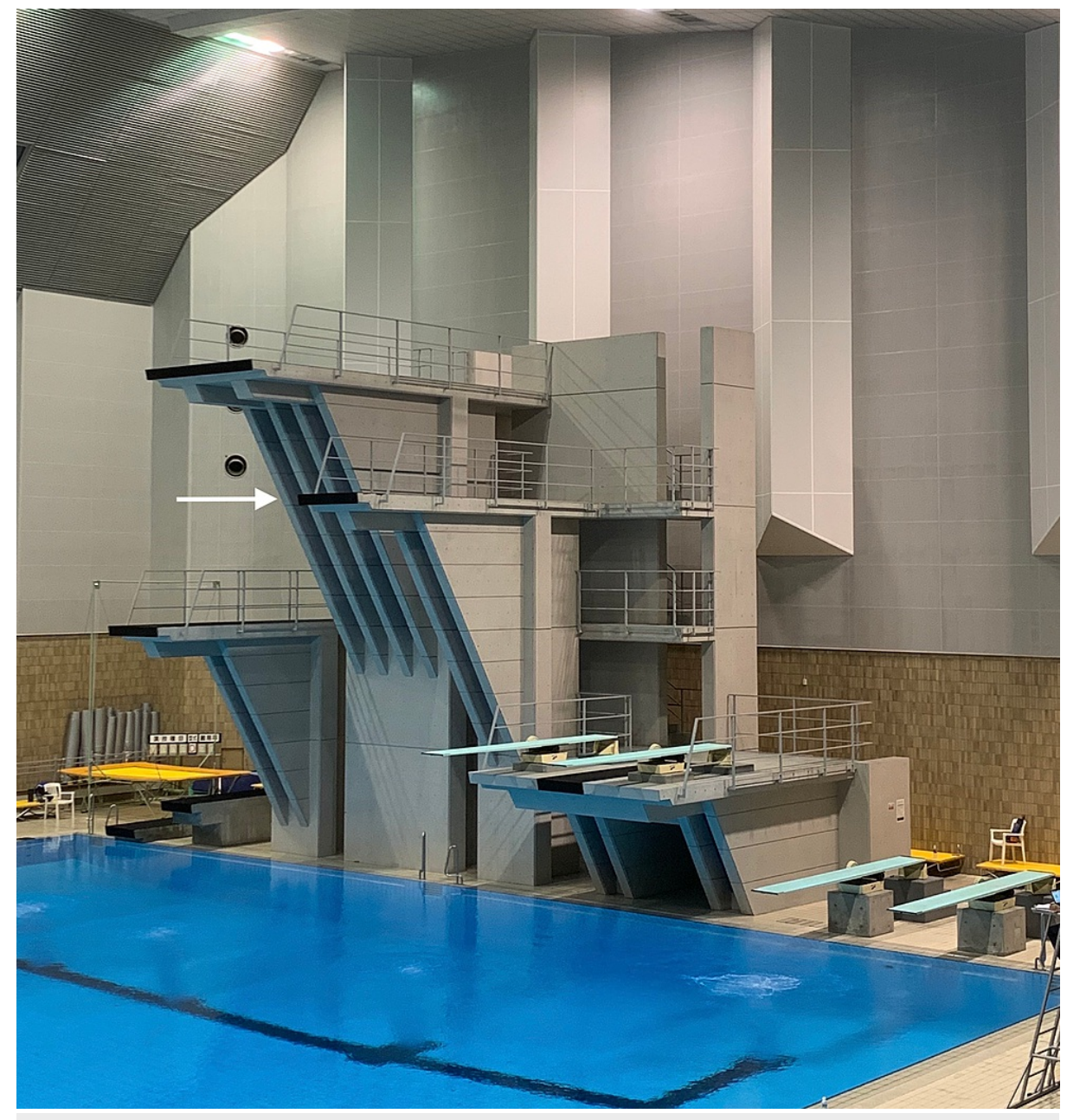

FIGURE 2: The diving pool with platforms and springboards.

The platforms are set at $5 \mathrm{~m}, 7.5 \mathrm{~m}$ (white arrow), and $10 \mathrm{~m}$. The springboards are set at $1 \mathrm{~m}$ and $3 \mathrm{~m}$.

At the first visit, she presented with upper left shoulder tenderness and left shoulder range of motion (ROM) limitation with passive flexion, abduction, and external rotation angles of $160^{\circ}, 150^{\circ}$, and $80^{\circ}$, respectively due to pain. Apprehension tests were negative. We were not able to detect any fractures or dislocation on Xray and computed tomography (CT) compared with the contralateral side, but magnetic resonance imaging (MRI) short-tau inversion recovery (STIR) imaging showed a high-intensity zone in the left lateral epiphysis of the proximal humerus (Figure 3). No bony Bankart lesions on CT or Hill-Sachs lesions were apparent. Because she had never had similar symptoms in the past, including on the contralateral side, we diagnosed her with traumatic growth plate injury caused by a single external force. Rest with sling and rehabilitation were initiated as conservative therapy. As a rehabilitation, muscle training and active ROM exercise within pain-free range were initiated for the first two weeks. After two weeks, the ROM ranges had gradually increased. 


\section{Cureus}
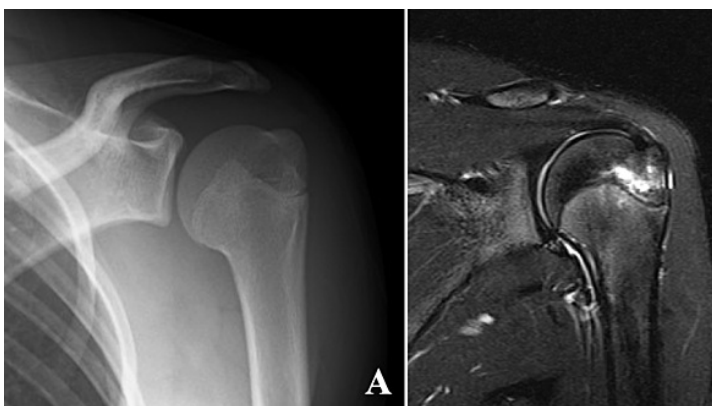

B

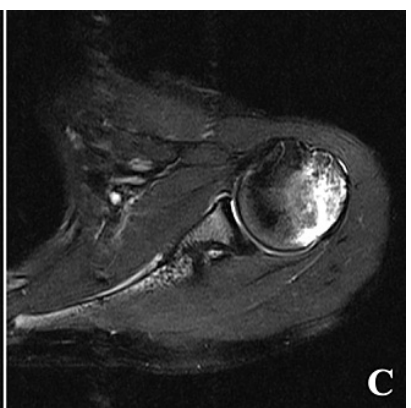

FIGURE 3: X-ray and MRI of the left shoulder at the first visit.

A, Frontal view of the X-ray. B, Coronary MRI STIR slice. C, Axial MRI STIR slice.

MRI, magnetic resonance imaging; STIR, short-tau inversion recovery.

At her visit four weeks post-injury, the left shoulder tenderness disappeared. The passive flexion angle was $180^{\circ}$, and the high-intensity zone in MRI STIR imaging decreased. She restarted handstand and feet-first diving practice from four and five weeks post-injury, respectively. The high-intensity zone in MRI STIR imaging had almost disappeared after six weeks post-injury (Figure 4), and she resumed hands-first diving practice. Moreover, she returned to the competition in springboard diving at eight weeks post-injury.
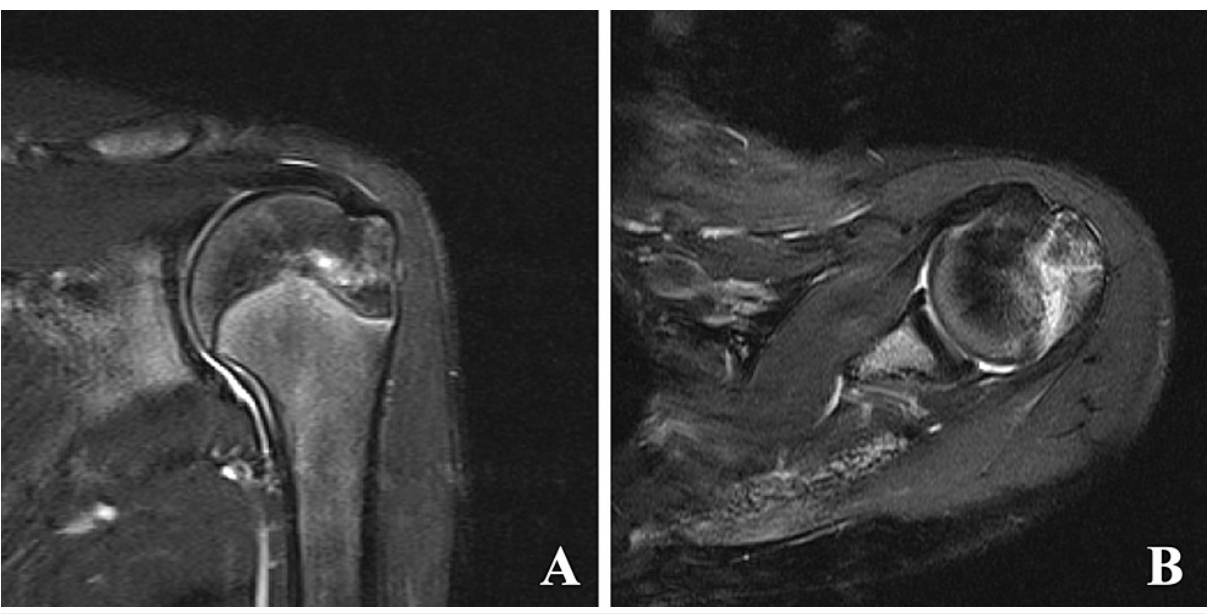

FIGURE 4: MRI of the left shoulder at six weeks post-injury.

A, Coronary MRI STIR slice. B, Axial MRI STIR slice.

MRI, magnetic resonance imaging; STIR, short-tau inversion recovery.

At her visit 12 weeks post-injury, shoulder ROM limitations were completely resolved with passive flexion, abduction, and external rotation angles of $200^{\circ}, 180^{\circ}$, and $110^{\circ}$, respectively; therefore, she restarted platform diving practice. Six months post-injury, she won a prize at a national diving competition. After more than two years of follow-up, there has been no reoccurrence of the symptoms.

\section{Discussion}

The mechanism of proximal humeral injury can be categorized into two types: first, by direct force caused by falling on the shoulder; second, by the indirect force caused when falling on an outstretched hand [2]. In competitive diving, athletes enter hands-first with outstretched hands; thus, we assume that the growth plate injury occurred by the axial impact experienced during hands-first diving.

When athletes perform hands-first diving from a $10 \mathrm{~m}$ platform, they reach a speed of about $14.1 \mathrm{~m} / \mathrm{s}(51$ $\mathrm{km} / \mathrm{h})$ at the moment of entering the water and decelerate to $9.25 \mathrm{~m} / \mathrm{s}(33 \mathrm{~km} / \mathrm{h})$ immediately. The decrease of speed is $4.85 \mathrm{~m} / \mathrm{s}$, and this is the same amount of impact we receive when we fall from $1.2 \mathrm{~m}$ to a hard surface [4]. Moreover, the shoulder is, in most cases, the endpoint to receive the water entry impact. In successful hands-first diving, the shoulder can absorb much of the water entry axial loading [5]. In failed hands-first diving, however, the shoulder may not be able to absorb the axial loading and is damaged. In this 
case, the athlete dived from a $7.5 \mathrm{~m}$ platform, but we expect that the axial impact the shoulder received was strong enough to cause the growth plate injury of the proximal humerus.

In competitive diving, injuries around the shoulder, lower back, and wrist are the most frequently reported $[3,6,7]$. Among shoulder-related injuries, shoulder joint subluxations and dislocations have been reported in diving athletes in the past [8]. Subluxation should be considered in this case; however, based on the negative apprehension tests and the absence of Bankart or Hill-Sachs lesions, we determined that subluxation is negative. Proximal humeral epiphysiolysis, which is known as Little League shoulder, shows similar MRI findings, and thus, should also be differentiated. Typically, it is common among young overthrowing athletes presenting with chronic shoulder pain, and physeal widening on X-ray is distinctive [9]. However, we consider it to be negative for the following reasons: first, competitive diving is not an overthrowing sport; second, no physeal widening was apparent compared to the contralateral side; third, the point of injury was clear; and fourth, the pain had not occurred before or recurred since.

Although injury reports in competitive diving are relatively few, the injury incidence is high. Between $92 \%$ and $100 \%$ of diving athletes reported injuries that required at least one week out of training [3]. In addition, the injury cases increased as the years of training and competition increased, were more common during practice than during competition, and were more frequent when diving from platforms than springboards. There was no gender difference, but water entry accounted for a large part of the injury mechanism among diving athletes [3]. In this case, a diving athlete with competition experiences from an early age was injured when entering the water during platform diving practice. Thus, this situation can be considered as having a high risk of injury.

Growth plate injury of the proximal humerus is a rare injury, representing $3 \%$ of all growth plate injuries in children [1]. Despite the low occurrence rate, growth plate injury of the proximal humerus can cause early growth plate closure, and thereby lead to angular deformity or length discrepancy [2]. Therefore, we must consider growth plate injury of the proximal humerus in the differential diagnosis.

The most common radiographic injury pattern of growth plate injury of the proximal humerus is reported to be type II injuries based on the Salter-Harris classification [2]. If the fracture line is apparent on X-ray, it can be diagnosed with this finding alone. Sometimes, however, X-ray findings are not clear; therefore, MRI, which is an excellent imaging method to depict epiphyseal injuries [10], is a better imaging option in cases like the one presented here.

\section{Conclusions}

We must consider growth plate injury of the proximal humerus in the differential diagnosis of shoulder pain. Subluxation and proximal humeral epiphysiolysis should be differentiated based on the patient's past medical history, the point of injury, physical examination, and imaging findings. Even if there is no sign of fracture or dislocation in patients with a suspected shoulder injury, we should consider taking an MRI if the patients are before the typical age of growth plate closure.

\section{Additional Information \\ Disclosures}

Human subjects: Consent was obtained or waived by all participants in this study. The institutional review board of Tsukuba University Hospital Mito Clinical Education and Training Center/ Mito Kyodo General Hospital issued approval 21-018. All procedures including review of the patient record used in this research were approved by the institutional review board of Tsukuba University Hospital Mito Clinical Education and Training Center/ Mito Kyodo General Hospital (No.21-018). Verbal informed consents were obtained from the patient and her parents to participate in this study. The institutional review board approved the study and the procedure outlined for the verbal consent obtainment. Conflicts of interest: In compliance with the ICMJE uniform disclosure form, all authors declare the following: Payment/services info: All authors have declared that no financial support was received from any organization for the submitted work.

Financial relationships: All authors have declared that they have no financial relationships at present or within the previous three years with any organizations that might have an interest in the submitted work. Other relationships: All authors have declared that there are no other relationships or activities that could appear to have influenced the submitted work.

\section{Acknowledgements}

We are grateful to Miki Omori, the medical clerk at the Mito Clinical Education and Training Center, University of Tsukuba Hospital, and Mito Kyodo General Hospital, for her contributions to data analysis. We would also like to thank Thomas Mayers, the assistant professor at the Medical English Communications Center, University of Tsukuba, for manuscript editing.

\section{References}

1. Neer CS 2nd, Horwitz BS: Fractures of the proximal humeral epiphysial plate . Clin Orthop Relat Res. 1965, 


\section{Cureus}

41:24-31.

2. Binder H, Schurz M, Aldrian S, Fialka C, Vécsei V: Physeal injuries of the proximal humerus: long-term results in seventy two patients. Int Orthop. 2011, 35:1497-502. 10.1007/s00264-011-1277-8

3. Rubin BD: The basics of competitive diving and its injuries . Clin Sports Med. 1999, 18:293-303. 10.1016/s0278-5919(05)70145-9

4. le Viet DT, Lantieri LA, Loy SM: Wrist and hand injuries in platform diving . J Hand Surg Am. 1993, 18:87680. 10.1016/0363-5023(93)90058-B

5. Jones NS: Competitive diving principles and injuries. Curr Sports Med Rep. 2017, 16:351-6. 10.1249/JSR.0000000000000401

6. Kim HC, Park KJ: Injuries in male and female elite aquatic sports athletes: an 8-year prospective, epidemiological study. J Sports Sci Med. 2020, 19:390-6.

7. Kerr ZY, Baugh CM, Hibberd EE, Snook EM, Hayden R, Dompier TP: Epidemiology of National Collegiate Athletic Association men's and women's swimming and diving injuries from 2009/2010 to 2013/2014. Br J Sports Med. 2015, 49:465-71. 10.1136/bjsports-2014-094423

8. Rubin BD, Chandler J, Anderson SJ, Kibler WB: A physiological and shoulder injury profile of elite divers Medicine and Science in Aquatic Sports. Miyashita M, Mutoh Y, Richardson AB (ed): Karger, Basel; 1993. 226-230. 10.1159/000423732

9. Heyworth BE, Kramer DE, Martin DJ, Micheli LJ, Kocher MS, Bae DS: Trends in the presentation, management, and outcomes of Little League shoulder. Am J Sports Med. 2016, 44:1431-8 $10.1177 / 0363546516632744$

10. Lurie B, Koff MF, Shah P, et al.: Three-dimensional magnetic resonance imaging of physeal injury: reliability and clinical utility. J Pediatr Orthop. 2014, 34:239-45. 10.1097/BPO.0000000000000104 